Books, videos, cd-roms, dvds and any other relevant items submitted for a review in the BDJ should be addressed to:

Mike Grace, Editor, British Dental Journal, 64 Wimpole Street WIG 8YS

\section{Orthodontic Management of Agenesis and Other Complexities}

\author{
M. Arvystas \\ London: Martin Dunitz, 2003 \\ price $€ 75$, pp227 \\ ISBN 1841841811
}

This book deals with multidisciplinary orthodontic treatment, particularly the management of hypodontia. The book is easy to read and the clinical photographs in the numerous case reports are generally of a very high quality.

The first chapter explores the history and theories of facial aesthetics including the concept of the 'golden proportion' and its relevance to dentofacial aesthetics. There is also a discussion of the common methods of cephalometric soft tissue analysis. The author concludes the chapter by reminding the reader that a good clinician must apply a combination of clinical and artistic judgement in treatment planning.

The second and third chapters deal in turn with the management of absent maxillary lateral incisors and premolars. Both chapters follow a similar structure with diagnosis and multidisciplinary treatment planning being discussed. All of the various treatment options are described using well-illustrated case records. These show examples of cases treated with orthodontic space closure, implants, and adhesive bridgework. There is also detailed discussion of the orthodontic mechanics employed in these cases and UK-trained orthodontists will notice a tendency towards nonextraction approaches with the use of nickel titanium arch expanders and lip bumpers. It was refreshing to see at least one example of a re-treatment case which is a problem encountered from time to time by most orthodontists yet is a topic infrequently dealt with in journals or textbooks. There is an extensive list of references at the end of each chapter.
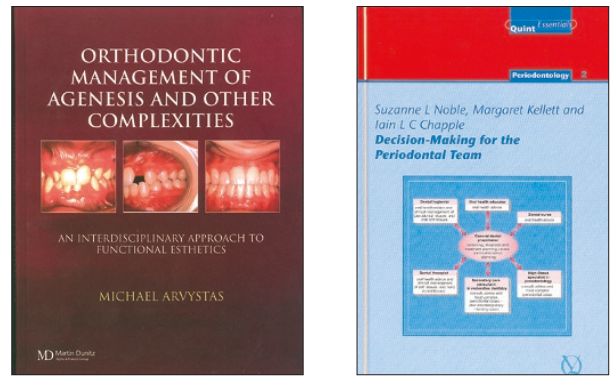

The final third of the book covers other types of multidisciplinary treatment including the management of difficult adult Class II Division 2 and long face/anterior open bite malocclusions. Although the reported cases are impressive in terms of treatment outcomes, the discussion of the treatments themselves is rather limited, particularly for those cases treated using a combination of orthodontics and orthognathic surgery. As a hospital orthodontist treating these types of cases on a regular basis, I found these chapters slightly disappointing in comparison with the earlier chapters of the book.

Overall however the reader will find this book an interesting read. The chapters on management of hypodontia are very good, and will certainly be of interest to most orthodontists and many restorative dentists, although the emphasis is on the orthodontic rather than restorative aspects of case management.

C. Johnston

\section{Decision Making for the Periodontal Team}

S. L. Noble, M. Kellett and I. L. C. Chapple
Surrey: Quintessence, 2003
price E28, pp159
ISBN 1850970637

This is a most useful little book on how to organise periodontal therapy in general, or for that matter, specialist practice. Written by three authors from different elements the dental team, including a university professor, a dental hygienist and an academic specialist in periodontics, the book takes the reader through an outline of the organisation of the periodontal team, including the medico-legal aspects of employing PCDs and the selection of surgical equipment.

The prevention and management of periodontal diseases are well covered and there are chapters on orthodontics, occlusion, and the periodontal-restorative interface. I particularly liked the hygienist prescription form, which is used by the dentist to transmit information to his hygienist about specific treatment measures for individual patients.

There is a short paragraph on posture for dental hygienists, which is unfortunately spoiled by a photograph of a dental hygienist working with poor posture. The text is illustrated with good quality colour photographs and flow charts, and the most important techniques in periodontal therapy are well described.

How to motivate the patient, the most commonly asked question at periodontal lectures, is well summarised in a chapter which leads on to a description of home care techniques for the patient. There is also an interesting section on smoking cessation, which dental hygienists with an interest in the subject will find it most useful.

The management of periodontal diseases is also concisely described, and there is a table of comparison of the main features of chronic and aggressive periodontitis. Unfortunately, the photograph of aggressive periodontitis, showing severely inflamed gingivae is not typical of the condition. The differences between periodontal and periapical abscesses is also described in a useful table, and I was particularly pleased to see a listing of selection criteria for specialist referral in periodontics.

My only criticism of this book is that the title does not describe the contents. For the most part, the book is a concise description of the management of periodontics in practice. Decisionmaking is only occasionally covered. The best exception to this is the helpful flow chart on the management of combined endodontic-periodontal lesions where decision-making would certainly be aided by referral to this page.

This useful book is part of the Quintessentials for General Dental Practitioners series and should be on every practice bookshelf. 